Following infection of the central nervous system the virus may multiply in the salivary glands, in the kidneys and elsewhere and in some species in the muscle and the lungs.

Rabies is enzootic in all countries, except Australia and Antarctica, existing in two forms: urban rabies, propagated principally in dogs, and rabies in wildlife. Wild carnivores appear to be the main transmitters of epidemic and endemic wildlife rabies and methods of control have been reviewed in detail elsewhere (WHO Report, loc. cit.). Some progress has recently been made in the treatment and prevention of rabies in man. Ideally, before instituting treatment it is important to determine whether the biting animal was vaccinated and whether the animal was rabid. Local treatment of the wound is extremely valuable, especially when applied very early after exposure. This is followed by the combined administration of anti-rabies serum, preferably of human origin, and active immunisation. In many countries an immunisation schedule of 14 to 21 daily injections is being used and booster doses are essential when combined antiserum-vaccine treatment is employed. A rabid patient should be isolated and treated in an intensive medical care unit.

The vaccines which have been used are of two types: those derived from the brain of adult or newborn animals and those derived from avian non-nervous tissue. Vaccine prepared from a Pasteur or similar strain of fixed virus grown in duck embyros has been developed in an attempt to eliminate the hazards associated with the brain tissue vaccine, which include neuroparalysis. Some progress has also been made in the purification of nervous tissue vaccines by extraction with fuorocarbon and other treatment. But even more promising are the vaccines produced in cell cultures. In the USSR and Czechoslovakia the Vrukovo-32 strain has been grown in primary hamster kidney cells, in France vaccine has been prepared in primary foetal bovine kidney cultures and in the USA and France an inactivated vaccine is being produced in human diploid cells with a Pasteurderived PM strain adapted to cell culture. Three injections of this vaccine, given at intervals of 3 to 4 days in previously non-immunised subjects, elicit a neutralising antibody response which is much greater than that induced by 12 to 14 daily injections of either brain tissue or duck embryo vaccine (WHO Report, loc cit.). Indeed evidence of studies to date indicates that cell culture vaccines offer distinct advantages over existing vaccines of nervous tissue or avian origin, from the points of view of both safety and potency. Clearly careful assessment and evaluation of the newly developed cell culture vaccines for man must continue. Pre-exposure immunisation of persons who run a high risk of repeated exposure, such as veterinarians and field naturalists, is highly desirable. Such immunisation consists of three injections of a potent vaccine at 5- to 7-day intervals followed by a booster injection a month later and subsequently at intervals of 1 to 3 years. Prophylactic vaccination of dogs and cats and other species where appropriate is most important, as are local administrative programmes and international control of transfer of animals. But the control of rabies in wildlife continues to challenge man's ingenuity.

\section{Nuclear reactor in the jungle}

from S. A. Durrani

An international symposium on the Oklo phenomenon was held at Libreville in Gabon on June 23-27, 1975 , under the joint auspices of the International Atomic Energy Agency (IAEA) and the French Atomic Energy Commission (CEA), and sponsored by the Government of Gabon.

Nature, it would seem, had anticipated man by something like 1,800 million years in bringing about the first selfsustained nuclear chain reaction on the Earth. And, contrary to common belief, it was not in the squash court of the University of Chicago in December 1942 , but in the wilds of what is today the Republic of Gabon at a place called Oklo that this fantastic phenomenon took place.

The history of the discovery of the phenomenon, as it unfolded during the symposium, is briefly as follows. In June 1972, a team working under the direction of Dr H. V. Bouzigues at the CEA service laboratory at Pierrelatte in France noticed a marked anomaly in the abundance of the uranium-235 isotope $(0.7171 \pm 0.0010$ in atomic per cent instead of the normal $0.7202 \pm$ 0.0006) during the certification of a secondary standard of $\mathrm{UF}_{6}$ by the gas diffusion method. Later, much larger depletions of this isotope were discovered (down to $0.621 \%$, and eventually to $0.296 \%{ }^{235} \mathrm{U}$ ) in uranium samples from this source, which was traced back to the Oklo deposit. First positive proof of the hypothesis that a natural chain reaction was responsible for the depletion of the fissile component was furnished by Mme $\mathbf{M}$. Neuilly and co-workers of CEA through the measurement of the ratios of fission-product rare earths detected in the ore by the spark source mass spectrometry technique. Two simul- taneous submissions by the above two groups on September 25, 1972, to the Proceedings of the Academy of Sciences, Paris, announced the discovery and the proposed explanation of this remarkable phenomenon. It was pointed out that at the time of the reaction the natural abundance of the relatively fast-decaying ${ }^{235} \mathrm{U}$ isotope was more than $3 \%$. This natural 'enrichment', helped by the moderation of the fission neutrons by the water content of the soil which enhanced their fission efficiency, and possibly by the relative absence of neutron-absorbing elements in the surroundings, allowed a nuclear chain reaction to develop. It is perhaps worth mentioning that such a natural chain reaction had already been predicted, on theoretical grounds, by several scientists, notably by $\mathrm{P}$. K. Kuroda as early as 1956 . The scientific secretary of the symposium, Dr R. Naudet of CEN, Saclay, has since late in 1972 been leading the 'Franceville Project' established by the French CEA to investigate the phenomenon, and has done a great deal to promote its study internationally.

One of the questions discussed at the conference (for example by E. Roth of CEN, Saclay) was whether the Oklo phenomenon was unique. The general feeling was that such propitious circumstances must have occurred elsewhere on the Earth. The timing $(\sim 1,800 \mathrm{Myr}$ ago) may well have been optimal. The role of organic matter in producing 'super-concentrations' of uranium in the Franceville basin was delineated by J. Connan (SNPA-Pau, France). At earlier times, organic matter may not have been present in sufficient quantities, whereas more recently the ${ }^{235} \mathrm{U}$ component would have diminished. One intriguing possibility being discussed in the corridors of the conference was whether the radiation accompanying Oklo-type reactions over the globe could have played a role in the furthering of the evolutionary process. (It is believed by some palaeontologists that the origin of mitotic nucleated cells lies somewhere between 1,500 and 2,000 Myr ago.)

The fact that most of the fission products seem to have stayed put over $\sim 1,800 \mathrm{Myr}$ has great relevance to present-day waste disposal problems in the field of nuclear reactors (and nuclear explosions). These implications were reviewed by $R$. D. Walton (Division of Waste Management and Transportation of USERDA) and by $C$. Fréjaques (CEA). The latter pointed out that ${ }^{230} \mathrm{Pu}$ seems to have hardly moved at all during its half-life of $\sim 24,000 \mathrm{yr}$. Such conclusions, if confirmed, would be of profound importance in the future development of nuclear energy, both peaceful and destructive. 